\title{
Representación online del movimiento estudiantil chileno: Reapropiación de noticias en Facebook
}

\author{
Online representation of Chilean students' movement: \\ News' re-appropriation on Facebook
}

\author{
Camila Cárdenas Neira \\ Universitat Pompeu Fabra, Departamento de Traducción y Ciencias del Lenguaje, \\ Grupo de Estudios del Discurso, Barcelona, España. \\ Correo electrónico: camila.cardenas.neira@gmail.com
}

\begin{abstract}
Este artículo analiza cómo los discursos que circulan en redes sociales modelan representaciones sobre la acción política del movimiento estudiantil chileno. El marco teórico-metodológico proviene de los Estudios Críticos del Discurso (ECD), cuyo enfoque socio-cognitivo permite indagar en los factores lingüísticos, epistémicos e ideológicos que inciden en las formas de auto y hetero-representación de los actores juveniles. El corpus se recoge de la fan page de Facebook "Estudiantes Informados" durante septiembre y diciembre de 2011, y se compone de noticias de la prensa online que recuperan sucesos polémicos sobre el conflicto educativo y sus respectivos comentarios. Se observa que la apropiación generacional de condiciones históricas y políticas resignifica los discursos periodísticos sobre la acción estudiantil, tensionando representaciones que redefinen el conocimiento social sobre los jóvenes movilizados.
\end{abstract}

Palabras clave: discurso online, acción política, movimiento estudiantil chileno, Facebook.

This article analyzes the ways in which circulating discourses in social networks shape representations about the political action of the Chilean students' movement. The theoretical and methodological framework come from Critical Discourse Studies (CDS), whose sociocognitive approach seeks to enquire about linguistic, epistemic and ideological factors that influence the ways of self and hetero representation of the youth actors. The corpus has been taken from the Facebook fan page "Estudiantes Informados" (Informed Students) during September and December 2011, and it comprises pieces of news from online press which retrieve controversial events related to the educational conflict and their associated comments. It is observed that the generational appropriation of historical and political conditions resignifies journalistic discourses about students' action, straining representations that redefine the social knowledge on mobilized youth.

Key words: online discourse, political action, Chilean students' movement, Facebook. 


\section{INTRODUCCIÓN}

Indagar cómo se representa la acción política juvenil en la historia reciente chilena constituye una exploración nueva desde los Estudios Críticos del Discurso (Cárdenas 2014a). Esta preocupación se desprende de un contexto más amplio en el que se registran las mayores movilizaciones sociales tras la recuperación de la democracia, en virtud de las cuales los estudiantes comienzan a desestabilizar distintas formas de invisibilización que, en las últimas décadas, promovieron sistemáticamente la negación, la marginación y el ocultamiento de su participación colectiva (Cárdenas 2011, 2012).

Los recientes ciclos de protesta estudiantil dan cuenta de los cambios que han experimentado las nuevas generaciones en relación con sus modos de comprender, identificarse y ejercer la política, a partir del abandono sistemático de las prácticas tradicionales de participación institucionalizada, y de la creciente adopción de prácticas de culturalización que configuran sus repertorios emergentes de acción. En este punto sobresale la incorporación de diversas tácticas tecno-políticas (Toret 2015), las cuales han favorecido un mejor aprovechamiento de sus prácticas mediales activistas (Mattoni 2013) dentro de la Web Social.

Desde el momento en que estas movilizaciones prefiguran nuevos emplazamientos para la interacción y la negociación política (Martín Rojo 2013), los estudiantes se posicionan públicamente como agentes discursivos con capacidad de incidir en espacios simultáneos de actuación y significación: las calles, las aulas y las redes sociales (Cárdenas 2014b). En ellos toman forma varias modalidades contenciosas tales como las manifestaciones y ocupaciones con marchas, intervenciones y performances registradas mediante fotografías y videos, la contestación lingüística en base a lienzos, pancartas y grafitis, y la creación gráfica de diseños como memes, caricaturas, afiches, etc. Dichos productos expanden el discurso estudiantil pues, a menudo, se propagan a través de estos espacios público-mediáticos de manera simultánea, fortaleciendo y potenciando los recursos y propósitos movilizatorios juveniles.

Una aproximación lingüística y socio-cognitiva a estas prácticas discursivas online es útil en virtud de dos supuestos. Primero, se requiere de una teoría multidisciplinar de la mediación (Van Dijk 2011, 2012) que releve la capacidad estratégica de los estudiantes para proponer a la sociedad síntesis subjetivas adecuadas a los contextos políticos y comunicativos en los que participan, es decir, para crear modelos mentales que sustenten interpretaciones sobre la realidad que impugnan mediante el lenguaje y otros sistemas semióticos. Segundo, se desprende que las identidades, las ideologías, los conocimientos y las memorias juveniles que se emplazan y adquieren significación en la Web Social juegan un papel relevante en la constitución de mecanismos de cohesión y solidaridad grupal, de modo que la interacción en red puede favorecer la alineación de representaciones sociales con las cuales validan el carácter, los fines y los alcances de su protesta.

Dicho esto, el análisis propuesto busca satisfacer cuatro objetivos: 1) describir los usos discursivos presentes en el Facebook de Estudiantes Informados entre septiembre y diciembre del 2011;2) identificar los esquemas ideológicos, identitarios y epistémicos configurados por dichos usos; 3) relacionar tales esquemas a los modelos de contexto que monitorean la comunicación online, y; 4) explicar cómo se construyen representaciones sobre la acción juvenil, relevando los factores sociales y políticos que circunscriben la participación del movimiento estudiantil. Con esto 
se espera echar luz sobre dos problemáticas: por una parte, cómo la gestión (contra) informativa llevada a cabo por los jóvenes movilizados pone en cuestionamiento el rol de los medios de comunicación tradicionales como constructores privilegiados de opinión pública, y, por otra parte, cómo el uso estratégico de las redes sociales confiere al movimiento estudiantil espacios de comunicación propios, dotándoles de recursos lingüísticos y cognitivos que les permiten posicionarse como interlocutores legítimos en el debate sobre la educación en Chile.

\section{MARCO TEÓRICO}

\subsection{Discursos, tecnologías y movimientos juveniles: De la calle a las redes sociales}

Los jóvenes secundarios y universitarios se han movilizado durante la última década (2006-2016) haciendo explícita una crítica sistemática tanto al modelo educativo (Torche 2005a, 2005b; Oliva 2008, 2010; Bellei y Cabalin 2013; Bellei, Cabalin y Orellana 2014), como al modelo económico neoliberal que lo sustenta (Mayol y Azócar 2011; Mayol 2012; Salinas y Fraser 2012; Somma 2012). En el país aún perviven varios de los denominados enclaves autoritarios del régimen militar (De la Maza 2010; Garretón et al. 2011), causantes de una democratización incompleta o restringida (Garcés 2013) que pone a la orden del mercado muchos de los derechos fundamentales básicos (Aguirre y García 2015). En este escenario, los estudiantes han identificado el derecho a una educación pública, de calidad y gratuita como "un punto de lucha primario de la posdictadura"1 (Arancibia, Sadlier y Montecino 2016: 333), instalando coyunturas inéditas de debate público para desvelar las lógicas de segregación y desigualdad imperantes en Chile, las que se corresponden, a su vez, con el mantenimiento y la vigorización de una jerarquía histórica subyacente a su estratificación social (Cabalin 2012, 2013, 2014).

Estas movilizaciones han condicionado la apropiación de nuevos espacios y prácticas de comunicación (Cárdenas 2014b), en razón de lo cual los jóvenes han podido integrar las funcionalidades que internet y las redes sociales proveen a los actuales movimientos sociales globales (Feixa, Pereira y Juris 2009; Tilly y Wood 2010; Tarrow 2011; Castells 2012, 2014; Bennett y Segerberg 2013; Feixa, FernándezPlanells y Figueras-Maz 2016). Su uso les ha permitido conectar directamente con la ciudadanía, controlando discrecionalmente la elaboración y la circulación de toda clase de mensajes con los que tornan inteligibles sus demandas y reivindicaciones colectivas (Cárdenas 2014c), combinando una multiplicidad de géneros textuales, visuales y audiovisuales, soportes mediales y sistemas sígnicos operativos en los entornos online. A partir de ello, dispositivos propios de la Web Social dan un nuevo carácter a los procesos de intercambio y de construcción colaborativa de discursos crecientemente contra-hegemónicos (Pardo Abril 2012), los que modifican las formas de producción, distribución y estabilización de significados que impactan en diversos niveles de la semiosis social (Kress 2010).

En un contexto donde predomina el descrédito general del movimiento estudiantil por parte de los medios masivos tradicionales (Aguilera 2008, 2010; Montecino

En adelante, las citas textuales en inglés han sido traducidas por la autora. 
2011; Pérez 2012, 2016; Arancibia, Sadlier y Montecino 2016), la utilización de canales alternativos de comunicación busca ejercer presión horizontal sobre los flujos informativos que suelen organizarse verticalmente para satisfacer los intereses de los grandes consorcios periodísticos (Costanza-Shock 2012, 2013). Una vez que los jóvenes reconocen que estos medios son en buena parte responsables de la negatividad con que la sociedad los percibe (Bennett 2007), el rol de auto-mediación que desempeñan las plataformas digitales interactivas (Castells 2007, 2009) les facilita el acceso a fuentes periodísticas distintas a las convencionales, y les permite compartir y socializar con otros a partir de contenidos afines a sus luchas y sus causas. Dicha predilección se fundamenta en la posibilidad de contrarrestar la concentración de la prensa oficial y el predominio de aquellas informaciones concebidas por los jóvenes como distorsionadas, desinformadoras u ocultadoras (Muñoz, Durán y Thayer 2014).

Estos cambios pueden comprenderse a partir de la noción de repertorios comunicativos, los cuales, según Alice Mattoni, abarcan “todo el conjunto de las prácticas mediáticas activistas que los (...) movimientos sociales podrían concebir como siendo posibles y desarrollándose (...) en las fases latentes y visibles de la movilización, para llegar a los actores sociales ubicados tanto dentro como fuera de sus dominios" (2013: 47). Esta autora propone clasificar las prácticas mediáticas activistas en dos tipos: a) prácticas de conocimiento medial, que aluden a la construcción de saberes específicos sobre el ecosistema mediático donde el movimiento se desenvuelve, y; b) prácticas mediales relacionales, que remiten al contacto con otros medios tecnológicos, empresas mediáticas y profesionales de los medios.

Dichos repertorios pueden llegar a afectar los modos de representación mediática dominantes, los cuales son tensionados por los sujetos movilizados cuando logran organizarse en espacios de interacción alternativos. Entre estos espacios, las redes sociales destacan en el último tiempo al consolidarse como contraesferas de enunciación, participación y deliberación (Millaleo 2011; Cárdenas 2014b, 2014c; Arancibia, Sadlier y Montecino 2016), con capacidad de regenerar y transformar muchas de las prácticas tecno-políticas de los movimientos. Dichas plataformas entregan un valor añadido a estas formas de mediación colectiva, siendo uno de sus rasgos más relevantes la posibilidad de tomar distancia de los medios masivos tradicionales. En esta dirección, se torna evidente la pluralización del espectro mediático, soportada por el carácter dialógico que involucra la comunicación digital mediada por computadora (Yus 2010; Herring 2013), en conjunto con la oportunidad de crear, administrar y poner en circulación textos propios con un carácter disidente (Pardo Abril 2012).

\subsection{Mediación, mediatización y meta-representación: Reapropiación noticiosa en Facebook}

De acuerdo a Neyla Pardo Abril (2009), la mediación es el proceso que da cuenta de cómo la cultura es interiorizada por los sujetos en la comunicación. En la actualidad, la mediación delimitada tecnológicamente deviene en mediatización. Para esta autora, la mediatización implica "la presencia de una significación modificadora de las prácticas y representaciones que caracterizan los distintos campos culturales” (2009: 55-56) en los que se incrustan los medios sociales. Por este motivo, el estudio de la mediatización abarca la revisión de sus efectos en la semiosis y en la interacción, con el propósito de explicar las variaciones en la relación sujeto-conocimiento y en la relevancia de lo informativo. 
Las prácticas comunicativas permiten delinear los modos en que las representaciones sociales (RS) se instancian, actualizan y sintetizan, proveyendo funcionalidad socio-cognitiva a los grupos que las incorporan. Las RS se desprenden, así, de las maneras como las comunidades se apropian de cierto objeto social cuando disponen de una multiplicidad de información circulante sobre él, pues según como se seleccione, articule y organice dicha información proceden formas de controlar el acceso al conocimiento que lo define (Pardo Abril 2007). En este sentido, el uso del lenguaje cumple un rol fundamental en la conformación, la permanencia y la desaparición de este saber colectivo, de allí el interés por analizar críticamente los discursos que posibilitan tales transformaciones.

Los discursos mediáticos cuentan con una potencialidad innegable para materializar y poner en contacto diversas RS. La noticia, en particular, tiene la capacidad de gestar y modificar los temas que adquieren o no más prestigio o valor social (Van Dijk 1990). Cuando la prensa representa determinados problemas sociales y participantes polémicos, aparece un conjunto de rótulos o etiquetas que definen las formas de ser de los grupos y las pautas orientadoras de su acción (Pardo Abril 2007). De esta manera, los canales informativos se configuran simultáneamente como portadores y constructores de las RS que allí se imponen, constituyéndose en los principales mediadores de los significados predominantes en juego.

Los medios de comunicación desempeñan un papel crucial en la reproducción de la hegemonía y del control moderno basado en el consenso ideológico (Van Dijk 2009). Esto es importante sobre todo en escenarios atravesados por relaciones de resistencia y oposición, porque el procesamiento discursivo influye en el control que ejercen las élites mediáticas sobre las mentes, los discursos y los comportamientos de la audiencia. En última instancia, el resultado de esa manipulación deriva en la construcción de sesgos, estereotipos o prejuicios sobre actores o acciones específicas que, a su vez, pueden extenderse a conocimientos, opiniones y actitudes más generales. Sin embargo, dicha influencia es siempre mediada y estructural (Van Dijk 2011, 2012).

En efecto, el discurso no interviene directamente en los individuos y las situaciones sociales donde participan, sino que lo hace a través de una interfaz sociocognitiva que modula a distintos niveles esa interacción. Desde esta perspectiva, los contextos son comprendidos como modelos mentales subjetivos que representan la experiencia social comunicada y monitorean su aprehensión por parte de los actores involucrados. Dichos modelos son de dos clases: a) los modelos situacionales que nos ayudan a esquematizar los eventos acerca de los cuales hablamos, y b) los modelos contextuales que representan las situaciones en las que hablamos. El discurso sintetiza así la función socio-cognitiva que es atribuida a las RS, conectando la memoria social (semántica) con la memoria personal (episódica) en toda interacción comunicativa. Son estos procesos los que garantizan una interpretación estratégica y no unívoca de los discursos periodísticos.

Uno de los aspectos fundamentales que propone esta teoría del contexto es la relación que se establece entre discurso y conocimiento (Van Dijk 2014). El modelo contextual ejerce un control general sobre el proceso de construcción y comprensión discursiva, "primero al controlar qué conocimiento general y qué información de los modelos situacionales (experiencias, noticias) expresar y presuponer en las estructuras semánticas globales y locales” (Van Dijk 2012: 156). Este autor plantea 
que el manejo del conocimiento es posible gracias a la existencia de un Dispositivo-C (K-device) "que interpreta como información el conocimiento del hablante-como se representa en los modelos mentales sobre eventos y como conocimiento compartido más general del mundo- y 'calcula' cuánto de este conocimiento los destinatarios comparten” (2012: 132). Por lo tanto, al estudiar los discursos mediáticos se debe diferenciar entre un nivel epistémico, que proporciona el marco para analizar la (re) construcción de los conocimientos comunicados, y un nivel funcional, que provee las categorías lingüísticas necesarias para el análisis de los textos que sintetizan conjuntos específicos de saberes colectivos.

La estrategia epistémica general en la producción del discurso consiste en que el conocimiento mutuo no necesita expresarse lingüísticamente (Van Dijk, 2002) y, por ende, puede permanecer implícito, ya sea porque se cree que el destinatario ya cuenta con él o puede inferirlo del conocimiento existente en la base común (common ground) (Van Dijk 2014). Cuando los usuarios del lenguaje se enfrentan a los discursos mediáticos, la condición básica para la comunicación de acontecimientos noticiosos es bastante similar a la que se aplica en la comunicación interpersonal: "presuponer que los destinatarios saben lo que nosotros (por ejemplo, el periódico) les contamos antes” (Van Dijk 2012: 136). Asimismo, se asume que muchas clases de conocimiento general o abstracto se comparten, así, inferimos "que los lectores tienen el mismo conocimiento sociocultural que yo tengo (o tenemos)” (Van Dijk 2012: 137-138). La función de la prensa consiste, precisamente, en impactar sobre esa base de saberes comunes para confirmarlos, o bien, modificarlos. En este punto es pertinente considerar, además, el problema de la manipulación y la distribución desigual del conocimiento y su abuso como recurso de poder (Van Dijk 2014).

Sobre este último aspecto, desde las conceptualizaciones clásicas de los esquemas de comunicación -la "aguja hipodérmica” (Lasswell 1927), el "modelo psicosocial” (Maletzke 1964), "la agenda setting” (McCombs y Shaw 1972), etc.- se ha establecido que los medios masivos regulan y constriñen la opinión pública en virtud de los intereses de los grupos hegemónicos (Sierra Caballero 2013). Esto se cumple, especialmente, cuando se trata de representar la protesta social y juvenil y construir conocimiento social sobre sus actores y acciones (Cohen 1973; Shoemaker 1984; Klandermans y Goslinga 1999; Boyle et al. 2005; McLeod 2007). No obstante, en la actualidad, la promoción de nuevos formatos informativos, especialmente aquellos derivados de los ciberperiódicos y los blogs de comentarios (Montecino 2011; Arancibia y Montecino 2013; Arancibia, Sadlier y Montecino 2016) y sus aplicaciones en redes sociales (Cárcamo y Sáez 2013), facilita que los individuos desarrollen nuevos patrones de lectura e interacción, permitiéndoles articular sus juicios, expresar sus sentimientos y experiencias a través de narraciones personales que, antes de la emergencia de estos géneros discursivos electrónicos, habían permanecido al margen de la esfera pública.

Las prácticas discursivas online contemplan, por tanto, no sólo nuevas formas de comunicación, sino también nuevos ejercicios políticos (Pardo Abril 2012), forjándose nuevos procesos estructuradores de significados que influyen en la visibilización y el intercambio de grupos históricamente marginados y considerados como minorías (Pardo Abril 2012). Con ello, se transforman los procesos verticales de comunicación (Castells 2007, 2009), desvelándose una serie de grietas en el control informativo (Rovira Sancho 2015), cuyo dominio deviene, así, en un campo de disputa. 
Por último, la reapropiación online de contenidos relevantes para la representación colectiva de los movimientos liga los procesos de mediación y mediatización aludidos a un tercer proceso denominado meta-representación (Pardo Abril 2009). Dado que dicha reapropiación implica el tránsito de unas tecnologías a otras, la expansión transmedial que se sucede cuando los discursos circulan y se conectan a través de distintas plataformas interactivas (Lemke 2005, 2009, 2013) deriva en la formación de representaciones sobre representaciones. Esta especificidad de la comunicación online equivale a una tercería (Pardo Abril 2009), la cual supone que los signos interactúan con quienes los producen, manipulan e interpretan, generando constantes efectos de resemiotización (Iedema 2003).

\section{Metodología}

\subsection{Caracterización y justificación del corpus}

La selección del corpus procede del siguiente recorrido: en primer lugar, se identificaron las principales páginas de Facebook que se originaron con las movilizaciones estudiantiles en el año 2011, eligiendo aquella que reunía más seguidores (297.448 a la fecha), denominada Estudiantes Informados (en adelante EI); en segundo lugar, se caracterizó el sitio en relación con sus patrones de publicación, para lo cual, junto con una observación general del total de entradas registradas desde agosto de 2011 (mes de creación de la fan page), se realizó una entrevista online a sus administradores; en tercer lugar, se establecieron criterios temporales para delimitar la elección de los discursos analizados, obteniéndose tres grupos que organizaron las entradas anuales $(2011,2012,2013)$, y; en cuarto lugar, se definieron criterios para determinar el nivel de popularidad de las entradas, priorizando aquellas que alcanzaron mayor cantidad de comentarios según la Interfaz de Programación de Aplicaciones que ofrece la biblioteca de Facebook.

Este análisis muestra resultados del periodo 2011 (septiembre a diciembre). El corpus está compuesto por 4 noticias (la más popular de cada mes) y sus respectivos comentarios (264 en total). Los textos se presentan en la Tabla 1:

Tabla 1: Corpus de análisis

\begin{tabular}{|c|c|c|c|}
\hline Fecha & Título de la noticia & Medio & $\mathrm{N}^{\mathrm{o}}$ de comentarios \\
\hline $27 / 09 / 11$ & $\begin{array}{l}\text { Confech acuerda iniciar diálogo sin retomar } \\
\text { clases y confirma movilización para el jueves }\end{array}$ & $\begin{array}{l}\text { Radio } \\
\text { Bío Bío }\end{array}$ & 26 \\
\hline $30 / 10 / 11$ & $\begin{array}{l}\text { Piñera y conflicto estudiantil: El gobierno } \\
\text { tiene la obligación de ser realista }\end{array}$ & $\begin{array}{l}\text { Radio } \\
\text { Cooperativa }\end{array}$ & 25 \\
\hline $05 / 11 / 11$ & $\begin{array}{l}\text { Piñera acusó obstrucción e intransigencia } \\
\text { ante dichos de Camila Vallejo }\end{array}$ & $\begin{array}{l}\text { Radio } \\
\text { Cooperativa }\end{array}$ & 53 \\
\hline $02 / 12 / 11$ & $\begin{array}{l}\text { Estudiantes interrumpen discurso de Piñera } \\
\text { y fueron sacados del teatro }\end{array}$ & Publimetro & 160 \\
\hline
\end{tabular}


En primer lugar, se observa que EI asume la gestión informativa bajo criterios de impacto y economía: por un lado, se eligen noticias cuyos contenidos resultan pertinentes e interesantes para sus seguidores, y, por otro lado, cuando estas son incorporadas en Facebook, se acompañan de palabras u oraciones breves para introducirlas o contextualizarlas. Si bien el análisis comprende la totalidad de la noticia, se reconoce el valor semántico-pragmático derivado de la reposición tal y como se publica en la fan page. En segundo lugar, se observa que los comentarios, con el paso del tiempo, comienzan a introducir otros recursos semióticos tales como emoticonos, imágenes y enlaces, pasando de ser predominantemente monomodales a multimodales. No obstante, el análisis se ocupa en esta oportunidad solo del contenido verbal.

\subsection{Modelo y categorías de análisis}

El análisis de los modos en que se representa discursivamente la acción política juvenil en redes sociales se fundamenta en las aportaciones de los Estudios Críticos del Discurso (ECD), cuyo enfoque socio-cognitivo asume una necesaria relación entre las prácticas comunicativas estudiantiles y los factores políticos e históricos más generales que circunscriben una de las movilizaciones sociales más relevantes dentro de la posdictadura chilena. Dicho enfoque se asienta principalmente en los trabajos de Teun van Dijk, con especial atención en sus teorías sobre contexto, ideología y conocimiento.

Las categorías previstas responden a una selección ad hoc al problema en estudio, y se relevan a partir de un conjunto de referentes teórico-metodológicos relativos al análisis del discurso online. La perspectiva de Yus (2010) sobre ciberpragmática 2.0 aplicada en páginas web, así como los trabajos de Lésmer Montecino y sus colegas (2011; Arancibia y Montecino 2013; Arancibia, Sadlier y Montecino 2016) sobre comentarios en blogs de opinión de ciberperiódicos, aportan las mayores convergencias en relación con el género discursivo analizado. Los planteamientos de Luisa Martín Rojo (2013) en torno a la construcción de paisajes lingüísticos y la ocupación discursiva de espacios online y offline enlazan los usos comunicativos de los actores movilizados a nuevos contextos móviles y dinámicos de producción e interpretación de textos de protesta. Mientras que las lecturas de Teun Van Dijk (2010a, 2010b, 2011, 2012, 2014), Neyla Pardo Abril (2009, 2012) y Eni Orlandi (2012) proveen aproximaciones focalizadas en el carácter representacional de los intercambios mediáticos.

En la Figura 1 se ofrece un ejemplo de publicación en EI. En la Tabla 2 se organizan las categorías consideradas, y luego se derivan sus relaciones y funcionalidad para el análisis. 
Figura 1: Ejemplo de la unidad de análisis “publicación” (entrada + comentarios) en EI

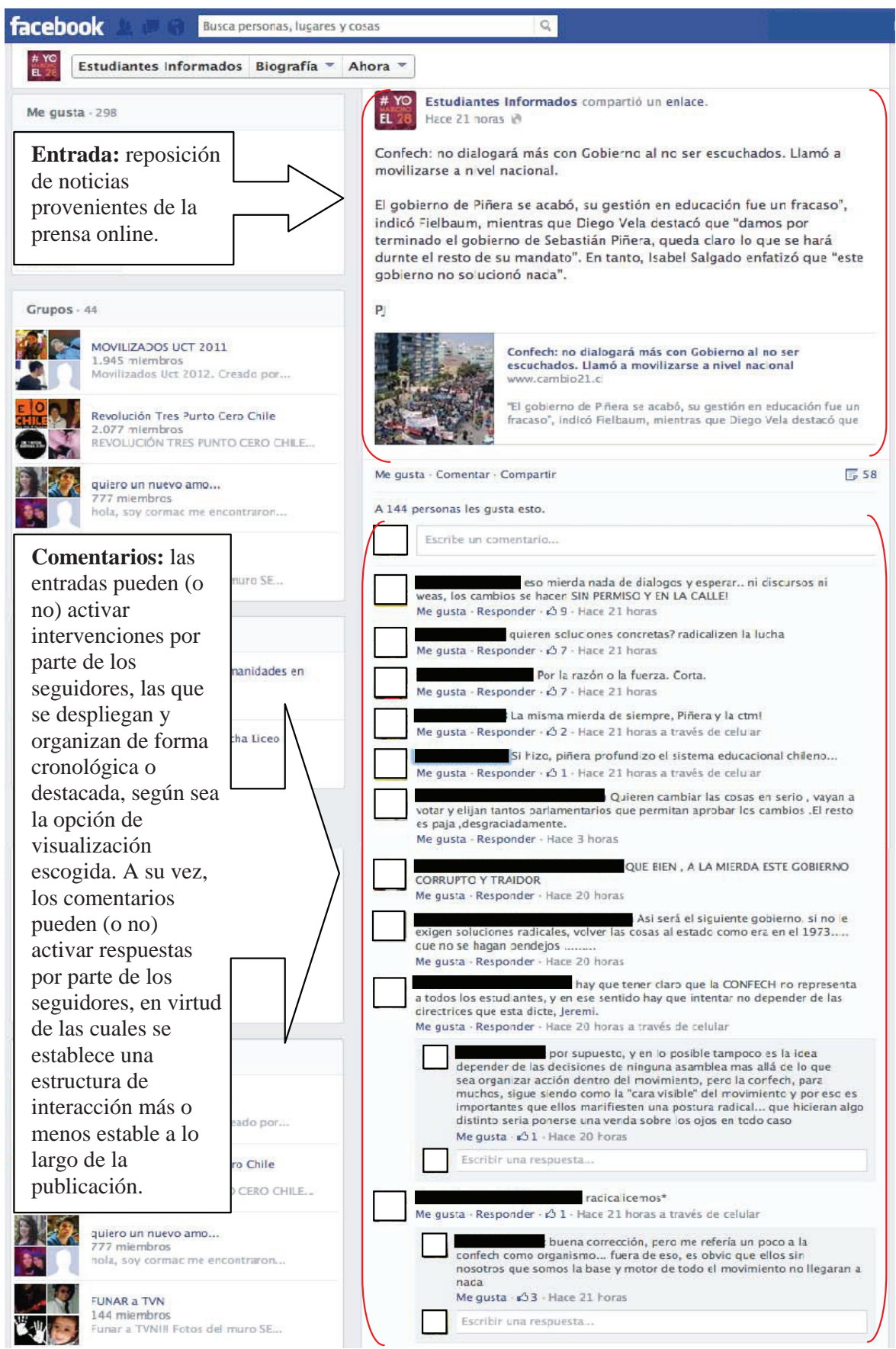


Tabla 2: Categorías de análisis y referentes teórico-metodológicos

\begin{tabular}{|c|c|c|}
\hline \multicolumn{3}{|l|}{ Usos discursivos } \\
\hline \multicolumn{3}{|r|}{ Representaciones sociales } \\
\hline Mediación & Mediatización & Meta-representación \\
\hline $\begin{array}{l}\text { Temas } \\
\text { (Pardo Abril 2007) }\end{array}$ & $\begin{array}{l}\text { Paráfrasis } \\
\text { (Orlandi 2012) }\end{array}$ & $\begin{array}{l}\text { Modelos de contexto } \\
\text { (Van Dijk 2011, 2012) }\end{array}$ \\
\hline $\begin{array}{l}\text { Descripción de los actores } \\
\text { (Van Leeuwen 2008) }\end{array}$ & $\begin{array}{l}\text { Polisemia } \\
\text { (Orlandi 2012) }\end{array}$ & $\begin{array}{l}\text { Conocimientos compartidos } \\
\text { (Van Dijk 2002, 2010b, 2014) }\end{array}$ \\
\hline $\begin{array}{l}\text { Implicaciones y presuposiciones } \\
\text { (Van Dijk 2010b) }\end{array}$ & $\begin{array}{l}\text { Relevancia } \\
\text { (Yus 2010) }\end{array}$ & $\begin{array}{l}\text { Ideologías grupales } \\
\text { (Van Dijk 1999) }\end{array}$ \\
\hline $\begin{array}{l}\text { Fuentes } \\
\text { (Pardo Abril 2007) }\end{array}$ & $\begin{array}{l}\text { Personalización } \\
\text { (Martín Rojo 2013) }\end{array}$ & $\begin{array}{l}\text { Identidades políticas } \\
\text { (Van Dijk 2010a) }\end{array}$ \\
\hline $\begin{array}{l}\text { Metáforas } \\
\text { (Lakoff y Johnson 1986) }\end{array}$ & $\begin{array}{l}\text { Polifonía } \\
\text { (Martín Rojo 2013) }\end{array}$ & $\begin{array}{l}\text { Memorias intragrupales } \\
\text { (Orlandi 2012) }\end{array}$ \\
\hline \multicolumn{3}{|c|}{$\begin{array}{lc}\text { Noticias } & \text { Comentarios } \\
\end{array}$} \\
\hline
\end{tabular}

El modelo analítico contempla que las prácticas comunicativas en redes sociales construyen modos de representación social sobre la base de tres procesos interrelacionados: mediación, mediatización y meta-representación. La mediación contempla un primer espacio de discursividad constituido por el tratamiento periodístico que reciben las movilizaciones estudiantiles. Dado que se accede a él mediante la reapropiación noticiosa llevada a cabo por los jóvenes en Facebook, la mediatización contempla este ejercicio de gestión (contra)informativa. Desde aquí se deriva un segundo espacio de discursividad conformado por los comentarios realizados a las noticias repuestas en EI. El proceso de meta-representación comprende la elaboración de RS sobre la acción política juvenil que es transversal a las publicaciones de la fan page, esto es, abarca la unidad de análisis en su conjunto (entrada: ${ }^{\text {noticia }}+$ comentarios: ${ }^{\text {intervenciones de los seguidores }}$ ).

\section{ANÁlisis del Corpus}

Se destacan 2 de las 4 publicaciones analizadas para ejemplificar el estudio, a saber, las noticias: (1) Confech acuerda iniciar diálogo sin retomar clases y confirma movilización para el jueves con 26 comentarios, y (2) Piñera y conflicto estudiantil: El gobierno tiene la obligación de ser realista con 25 comentarios. Ambas dan cuenta de aspectos complementarios del conflicto educativo, y construyen representaciones sociales sobre la acción política juvenil con base en posicionamientos contrapuestos, proporcionando una perspectiva más integrada del problema en cuestión. 


\subsection{Ejemplo $(1)^{2}$}

Esta publicación es distintiva de los primeros meses de movilizaciones estudiantiles, caracterizados por sucesivos intentos de negociación política para resolver el conflicto. En este escenario, mientras el gobierno propone escasas medidas resolutivas y supedita el diálogo al término de las protestas, los jóvenes profundizan su acción mediante la ocupación de establecimientos educativos y sucesivas marchas y paros nacionales.

Figura 2: Noticia (1) repuesta en el Facebook de EI

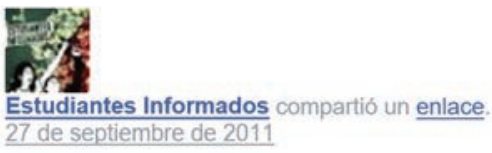

Tras más de 12 horas de discusión, la Confederación de Estudiantes de Chile (Confech) decidió iniciar la mesa de diálogo en La Moneda, pero sin retomar las clases y confirmando la movilización para el jueves 29 de septiembre.

biobiochile - Confech acepta iniciar la mesa de diálogo con el Gobierno www. biobiochile.cl

biobiochile - Confech acepta iniciar la mesa de diálogo con el Gobierno

116 me gusta 26 comentarios 1 compartir

\section{- Mediación}

Esta noticia es la única dentro del corpus que otorga a los estudiantes un papel protagónico. La Confederación de Estudiantes de Chile es foco y tema del titular y de gran parte del cuerpo. Su decisión de iniciar la mesa de diálogo constituye la macroestructura semántica del texto, de modo que los sentidos locales que se desprenden de ella sirven continuamente al propósito de especificar las condiciones en que esta resolución se produce. En todas las cláusulas los hechos son relatados desde la perspectiva de los estudiantes movilizados, quienes abarcan procesos verbales ( 'indicaron', 'sostuvieron', ‘hicieron un llamado’, etc.) y mentales ('decidió’, 'aceptaron', 'destacaron', etc.) en virtud de los cuales se precisan sus dichos y puntos de vista, respectivamente. Tanto la Confech como los universitarios y secundarios aparecen como participantes grupales y activos, generalizados a partir de su quehacer como colectivo político, mientras que el gobierno y el parlamento se describen como participantes pasivos y reactivos ante las acciones de los primeros. Ambos se representan como adversarios en iguales condiciones de poder, dada la presión social que ha impuesto el movimiento en los últimos meses de manifestaciones.

Adicionalmente, las principales fuentes empleadas corresponden a las voces de los dirigentes juveniles, cuyas declaraciones se introducen de manera indirecta para explicitar las decisiones y circunstancias que posibilitan el diálogo institucional. Entre las implicaciones y presuposiciones presentes destacan aquellas que aluden

Se puede acceder a la noticia completa en: http://goo.gl/X1QHhf 
a la dificultad de lograr una decisión consensuada entre las bases estudiantiles, al imperativo de no defraudar a sus miembros, y a la necesidad de aprovechar el apoyo ciudadano para incidir en la votación de la Ley de Presupuesto 2012, donde la Confech busca conseguir el aumento de los fondos basales destinados a la educación superior. Para enmarcar esta disputa sobresalen dos tipos de metáforas: los 'parches' remiten a soluciones inmediatistas y efectistas que no resuelven estructuralmente la crisis educativa, mientras que la 'lucha' da cuenta de la confrontación simbólica -ideológica y de fuerza- entre los estudiantes y el gobierno, que la mesa de trabajo pretende justamente destrabar.

\section{- Mediatización}

En la reposición efectuada por EI, el énfasis informativo está puesto en la disyuntiva de dar continuidad a las movilizaciones pese a la oportunidad que supone abrir una negociación con el gobierno. La recontextualización de esta noticia tiene por objetivo reformular los sentidos conferidos al diálogo político. En esta dirección, los comentarios de los seguidores revelan distintas posturas en confrontación, habitualmente configuradas a partir de la estructura nosotros $\mathrm{v} / \mathrm{s}$ ellos $\mathrm{y}$, en menor medida, por la utilización de ciertas metáforas e ítems léxicos de valoración negativa inscrita, en ocasiones de carácter coloquial y ofensivo. De este modo, el diálogo puede interpretarse como: a) una predisposición de acuerdo, es decir, con una actitud favorable hacia las respuestas del gobierno (i.e.: ICL: "tampoco hay que cerrarse... lo mejor es buscar instancias, siempre velando eso sí por lo que queremos conseguir como movimiento ${ }^{3 ”}$ ); b) una demostración de debilidad (i.e.: YHG: "chao con el Gobierno nosotros tenemos nuestras propias decisiones...”); c) una amenaza (i.e.: SM: "yo no me rendiré hasta tener educación gratuita y de calidad para todos, así que aunque quieran cagarnos [perjudicarnos] será sobre mí y sobre muchos otros!!! La lucha sigue...”), y; d) una traición (i.e.: VV: “se está tranzando y vendiendo, reformistas de mierda”), todo lo cual pone en jaque las normas y valores del movimiento.

Esta diversidad de posturas confirma que el tema instalado por la reposición noticiosa es altamente relevante para la comunidad de $E I$, pues visibiliza la importancia de un debate que evalúa hasta qué punto es posible institucionalizar la lucha estudiantil sin perder los apoyos de las bases ni desatender las demandas de origen. Al respecto, mientras algunas intervenciones muestran confianza en las garantías que aseguran la permanencia de las movilizaciones, sobresalen aquellas que buscan criticar a los dirigentes estudiantiles por no supeditarse al sentir de las mayorías. Los argumentos esgrimidos por estas voces resultan personalizados por su impronta generacional: por un lado, se recuerdan antiguas coyunturas de negociación donde la movilización se vio frustrada por la cooptación de los gobiernos de turno, y, por otro lado, se advierte la posible injerencia de los partidos políticos al interior de la Confech, cuestión que invalidaría la legitimidad del diálogo al fraguarse en condiciones que son de antemano desautorizadas por sus miembros.

Las mayúsculas corresponden a las iniciales de los nombres de los comentaristas. Los errores ortográficos se han corregido en la transcripción. 


\section{- Meta-representación}

El modelo de contexto se reconstruye a partir de un conjunto de indicios lingüísticos, tales como nominalizaciones, deícticos y complementos circunstanciales, en razón de los cuales se designan a los participantes y se especifica el eje espacio-temporal básico que enmarca la situación comunicativa. También resulta necesario derivar de ciertas estructuras semánticas y pragmáticas una serie de inferencias en torno a variables menos evidentes, como sucede con la determinación de roles sociales y objetivos políticos intervinientes.

Según consigna la noticia, el escenario contingente está dado por la proximidad de la votación parlamentaria sobre la Ley de Presupuesto 2012, no obstante, los comentarios que se desprenden de la reposición en EI configuran un escenario levemente diferente, donde adquieren centralidad las condiciones de coacción gubernamental que circunscriben la conformación de la mesa de diálogo. Los principales actores confrontados son la Confech y el gobierno, aunque la noticia alude también a otros actores secundarios: los ciudadanos (participante grupal generalizado, en posición paciente), los trabajadores de las universidades (participante grupal genérico, en posición activa), la Asamblea Coordinadora de Estudiantes Secundarios (ACES) y el congreso (participantes institucionales colectivos, en posición activa los primeros y en posición reactiva los segundos). Los comentarios, a su vez, añaden otros actores críticos al conflicto educativo: los partidos políticos (participante institucional colectivo, en posición activa), quienes son representados como enemigos del movimiento (y de la sociedad, en general), y el pueblo y otras organizaciones y movimientos sociales (participantes grupales generalizados, en posición activa), quienes son representados como simpatizantes y aliados del movimiento.

En la noticia los estudiantes son los únicos que ocupan un rol como agentes discursivos, no obstante este protagonismo, en los comentarios se observa que el rol político atribuido a los dirigentes juveniles es relativizado y puesto en duda, esto es, se distingue a la directiva de la Confech de las bases conformadas por los universitarios y los secundarios, así como sus actos e intencionalidades. Asimismo, pese a que la noticia no otorga voz ni agencia al gobierno, los comentaristas modelan acciones asociadas con actitudes maliciosas y deshonestas. Con base en estas referencias, la definición de los objetivos es un elemento polémico del modelamiento cognitivo. Aunque la noticia solo da cuenta de la disposición a dialogar entre las partes, las intervenciones en EI postulan que estos propósitos resultan individualizados al margen de si representan los intereses del gobierno o de los estudiantes, es decir, estos no estarían traduciendo demandas sectoriales sino motivaciones políticas particulares. En esta línea, hay concordancia a la hora de cuestionar el sentido de la negociación, interrogándose la pertinencia de una medida que, por pertenecer al ámbito institucional -vertical y jerárquico- tensiona las lógicas del poder juvenil -horizontal y descentrado-. En este punto, la discusión propuesta en los comentarios revela en distintos momentos una disposición analítica y crítica por parte de los seguidores, quienes recontextualizan los contenidos informativos desde un posicionamiento más bien resistente.

En cuanto al modelo epistémico subyacente, para un adecuado procesamiento discursivo de la noticia resulta necesario compartir conocimientos generales sobre el decurso de las movilizaciones recientes, vale decir, antecedentes sobre los petitorios 
exigidos, los programas de acción ejecutados, las medidas de presión contingentes, etc. Sobre esta base, los comentaristas aportan otros conocimientos específicos que son sugeridos a partir de la reposición. Un conocimiento relevante dice relación con la experiencia de negociación que marcó el término de la Revolución Pingüina del año 2006, este se presenta como dado en el fondo común (common ground) de los interlocutores, y se activa desde la memoria semántica con el fin de advertir el riesgo que supone establecer nuevamente un diálogo con el gobierno. Otro conocimiento evidenciado alude a la confrontación de dos concepciones de la práctica política, a saber, una perteneciente a las bases ciudadanas auto-organizadas, en contraposición con otra proveniente de los partidos que buscan hacer proselitismo con las demandas estudiantiles. Este conocimiento también se presume compartido por los miembros del movimiento, pero es enfatizado en la discusión online con el fin de enmarcar sus esquemas de acción colectiva. Véanse algunos ejemplos en la Figura 3.

Figura 3: Ejemplos de comentarios realizados a la noticia (1) en el Facebook de EI

\footnotetext{
perro entiendo lo que sientes, pero a no abandonar la lucha! si nos van a cagar esta vez vamos a estar vivitos, no como cuando se abrazó la concerta y la derecha y nos cagaron en 2006, eso no pasará estamos maduros por eso cabros si el gobierno eso quiere, pongámosle aún más empeño !! 27 de septiembre de 2011 a la(s) 20:47 · $\underline{3}$
}

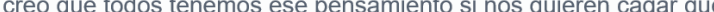
pasen por encima de todos nosotros, y los partidos siempre querrán aprovechar esto pero comenten errores y ya todos saben que confiar en partidos no sirve acá lo que sirve es el PODER REAL POPULAR que somos todos nosotros que organizamos, movilizamos con un solo interés que LA IGUALDAD PARA TODOS.

27 de septiembre de 2011 a la(s) 21:03 · 1
\end{abstract}

Ambos conocimientos se configuran mediante ciertas metáforas (SB: "como cuando se abrazó la concerta [Concertación de Partidos por la Democracia] y la derecha”, "que pasen por encima de nosotros"; EGG: "el poder real popular que somos todos nosotros"), algunos usos coloquiales propios de la jerga juvenil (SB: "si nos van a cagar esta vez vamos a estar vivitos"), y la utilización de conectores de contraexpectativa (EGG: "los partidos siempre querrán aprovechar esto pero cometen errores”) en conjunto con expresiones evidenciales (EGG: “y ya todos saben que confiar en partidos no sirve").

Con respecto al esquema ideológico, la noticia aporta escasas evidencias sobre el posicionamiento del movimiento estudiantil, únicamente sobresalen algunas referencias a la acción directa (continuidad de paros, marchas y huelgas de hambre) que se desprenden de la paráfrasis a los dichos de los dirigentes juveniles. En los comentarios registrados en $E I$, en cambio, resulta notorio que la ideología que parece transversal a las actitudes de los estudiantes es anti-capitalista, en razón de la cual se rechaza la intromisión del mercado en el campo de los derechos sociales (i.e.: SB: "esto [el movimiento] se levantará las veces que sea necesario, hasta vencer!!! Porque todos los que estamos apoyando sabemos que la educación debe ser un derecho no un privilegio!!!”). En menor medida, surgen menciones a una ideología anti-fascista, aunque en las intervenciones no se clarifica a qué remiten estas posturas exactamente, salvo la alusión global a la derecha política representada en el gobierno de Sebastián Piñera (i.e.: "VV: "EL JUEVES LE DIREMOS NO A LA CONFECH 
Y AL FASCISMO!!! QUE VIVAN LOS QUE LUCHAN!!!”). En estos ejemplos se reiteran determinadas estrategias discursivas que son habituales en el corpus, como la distinción del endogrupo mediante la utilización del nosotros inclusivo, y el empleo de metáforas típicas de los movimientos sociales vinculadas con acciones como levantarse, luchar y vencer.

Finalmente, el esquema identitario se reconstruye parcialmente en virtud de ciertos valores compartidos por los estudiantes movilizados, los cuales refieren fundamentalmente a la búsqueda de igualdad y bien común. En este sentido, la identidad que prevalece entre los jóvenes es una de índole moral y de inspiración transformadora, que los caracteriza como dispuestos y comprometidos con el cambio social. Un componente que parece ser transversal a todos ellos corresponde a la responsabilidad de restituir a la ciudadanía sus derechos fundamentales (i.e.: SB: "el pueblo ya se levantó y no es por los comunistas ni menos por la concerta, es porque recuperó la memoria, de que antes los derechos se respetaban y eso ya es una gran victoria!! Ahora hay que seguir por la más grande la educación como fin social!!”). Como se deriva del comentario anterior, parte de este compromiso conecta con una memoria sensible dentro del pasado reciente chileno. Así, por ejemplo, se reconoce que el modelo educativo vigente constituye una herencia del régimen militar (i.e.: ICL: "esta mierda de sistema impuesto en dictadura (...) llamado NEOLIBERALISMO... VA A CAER”). Con ello se deduce que la principal tarea impuesta por las movilizaciones estudiantiles actuales es una de carácter histórico, esto es, radica en refundar este modelo con base en una verdadera experiencia democrática que excluye cualquier tipo de resabio dictatorial.

\subsection{Ejemplo (2) ${ }^{4}$}

Esta noticia da cuenta de las declaraciones que realiza el ex presidente Sebastián Piñera a un periódico extranjero. Dado que las movilizaciones estudiantiles han logrado gran visibilización y adhesión ciudadana, Piñera se ve apelado a opinar sobre los alcances de las manifestaciones que ocupan desde hace meses un lugar destacado en la agenda informativa.

Figura 4: Noticia (2) repuesta en el Facebook de EI

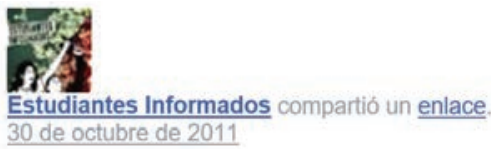

El Presidente Sebastián Piñera, en entrevista con el diario El Pais de Uruguay, indicó que el gobierno tiene el deber de ser "realista" a la hora de enfrentar las demandas del conflicto estudiantil, momento en el que también reiteró que la educación es "la madre de todas las batallas".

Piñera y conflicto estudiantil: El gobierno tiene la obligación de ser realista www.cooperativa.cl

Mandatario fue entrevistado por el diario El País de Uruguay durante su reciente gira a la zona. "LoS estudiantes quieren todo aquil y ahora", sostuvo.

10 me gusta 25 comentar 2 compartir

Se puede acceder a la noticia completa en: http://goo.gl/C0W5YF 


\section{- Mediación}

Esta publicación es característica del tipo de informaciones que circula habitualmente en la prensa tradicional sobre el movimiento estudiantil, cuyo rasgo más sobresaliente consiste en abordar las acciones de los jóvenes desde la perspectiva de las autoridades políticas. En (2) el tema principal corresponde al posicionamiento que mantiene el gobierno ante el conflicto educativo. Los actores mencionados son el ex presidente Sebastián Piñera (individual y especificado, activo) y el gobierno (institucional y colectivo, activo), por un lado, y los estudiantes, concretamente los universitarios (grupal y genérico, reactivo), por el otro. La relación de poder que se establece entre ellos es asimétrica, y se construye simbólicamente a partir de la disyunción adultocentrismo/infantilismo (i.e.: "el gobierno tiene el deber de ser realista” / "los estudiantes quieren todo aquí y ahora”). La única fuente empleada en el texto es la voz del ex presidente, cuyos enunciados se introducen para evaluar positivamente la actitud comprometida, madura y cautelosa del gobierno, y como contraparte criticar la actitud idealista, radical y precipitada del movimiento. En todos los casos sus acciones corresponden a procesos verbales ('indicó', 'reiteró', 'puntualizó', 'explicó', 'sostuvo', 'sentenció', etc.). De hecho, Piñera es foco y tema de casi la totalidad de las cláusulas, las que se constituyen mayoritariamente a partir de la inserción directa -y en extenso- de sus dichos.

En esta noticia se distinguen dos recursos lingüísticos que potencian inferencias interesantes: los deícticos ‘aquí y ahora’ y la conjunción adversativa 'pero’. Tal como se observa en un ejemplo previo, los deícticos funcionan para intensificar el requerimiento de los estudiantes con una valoración negativa evocada. Se connota con ello que la inmediatez de los cambios exigidos al sistema educacional entronca con la obligación del gobierno de tomar decisiones meditadas y responsables, es decir, "realistas" según las palabras de Piñera. Otro ejemplo que grafica el uso de conjunciones para crear implicaciones va en una dirección similar (i.e.: "los estudiantes están pidiendo educación gratuita para todos pero un gobierno no puede pensar solo en los universitarios”), esto es, se presupone que las reformas no deben hacerse cargo exclusivamente de la educación superior, sino también de los demás niveles educativos y, eventualmente, de otros asuntos sociales. A partir de estas declaraciones se infiere que los jóvenes no hacen bien en promover un beneficio sectorial cuando hay otros problemas de los cuales el gobierno debe ocuparse, especialmente si estos atañen a necesidades de la sociedad en su conjunto. La utilización de conectores de contraexpectativa es abundante en el discurso de Piñera, y sirve para generar concesiones relativas a la obligación de palear la crisis de la educación, aunque sin apegarse a los petitorios ni a los plazos de acción que reclaman los estudiantes (i.e.: “Todos quisiéramos ir más rápido pero hay que tener cuidado”).

Finalmente, la noticia registra numerosas metáforas destinadas a comprometer al gobierno con el mejoramiento del modelo educativo (i.e.: "mejorar la calidad de la educación en todos los niveles es la madre de todas las batallas"), y demostrar sus avances en la materia (i.e.: "El gobierno dio pasos gigantescos en el tema de la educación”). Además, estos usos buscan mitigar los efectos que acarrean los altos costos de la educación universitaria (i.e.: "porque para muchas familias eso [el financiamiento] constituye una mochila extraordinariamente pesada”), y las repercusiones que supondría dar cumplimiento a las demandas del movimiento, 
principalmente a la gratuidad ("no [podemos] pretender vivir más allá de nuestros medios (...) va a frenar el desarrollo”).

\section{- Mediatización}

En la reposición efectuada por EI, el énfasis informativo está puesto en la negativa del gobierno a satisfacer las demandas estudiantiles. La recontextualización de esta noticia cumple en su origen una función metalingüística implícita, a saber, discutir qué significa exactamente ser "realista" según consigna Piñera en sus declaraciones, y, a partir de ello, estimular un debate acerca de cuáles son los parámetros (morales, sociales, políticos y económicos) que se delimitan con esta noción. En esta dirección, se busca cuestionar el carácter construido de la realidad, particularmente cuando son los poderosos quienes cuentan con la autoridad de determinar las condiciones de posibilidad de ciertos hechos o acciones (i.e.: RCJ: "Para los políticos actuales no hay más realismo que aplicar represión en vez de responder a la raíz del problema”). De este modo, los comentarios giran en torno a la factibilidad de dar solución "real” a las demandas del movimiento, y se centran en el carácter gratuito de la educación, aspecto polémico que entonces aún no presentaba consensos dentro de la clase política y de la sociedad en general. En contadas ocasiones se registran comentarios que critican las reivindicaciones estudiantiles por parecer antojadizas o inconsistentes, no obstante, desencadenan interesantes intercambios que configuran al menos dos representaciones nucleares en disputa: "la educación como derecho" vs. "la educación como fruto del esfuerzo individual”. Véanse algunos ejemplos en la Figura 5.

Figura 5: Ejemplos de comentarios realizados a la noticia (2) en el Facebook de EI

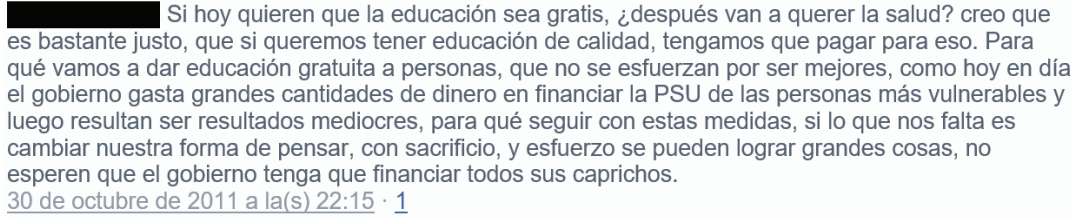

Si hoy quieren que la educación sea gratis, ¿después van a querer la salud? creo que es bastante justo, que si queremos tener educación de calidad, tengamos que pagar para eso. Para qué vamos a dar educación gratuita a personas, que no se esfuerzan por ser mejores, como hoy en día el gobierno gasta grandes cantidades de dinero en financiar la PSU de las personas más vulnerables y luego resultan ser resultados mediocres, para qué seguir con estas medidas, si lo que nos falta es cambiar nuestra forma de pensar, con sacrificio, y esfuerzo se pueden lograr grandes cosas, no esperen que el gobierno tenga que financiar todos sus caprichos. 30 de octubre de 2011 a la(s) 22:15 1

No son caprichos y no solo cambiando la mentalidad se va a lograr que los mediocres como dices tú sean algo más si no que tiene que haber un cambio desde el principio y también tiene que haber un cambio de proyecto país 30 de octubre de 2011 a la(s) 22:19 1

De todos modos me gusta el argumento de pobres con pobres ricos con ricos. Así seguiremos siendo el 2ndo país del mundo con mayor segregación social 31 de octubre de 2011 a la(s) 11:12

En el primer ejemplo destaca la utilización de recursos lingüísticos de modalización tales como preguntas retóricas, finitos de probabilidad ('creo que', 'se puede lograr') y adjuntos de polaridad negativa ('no esperen que el gobierno') para deslegitimar la lucha por la gratuidad. En el segundo ejemplo sobresalen recursos lingüísticos de modulación tales como adjuntos de obligación ('tiene que haber un cambio') y de polaridad negativa ('no son caprichos') para responder y confrontar el comentario precedente. En ambos casos es notoria la función del esquema nosotros v/s ellos 
que orienta la producción de argumentos y organiza la interacción online. El recurso a la ironía presente en el tercer ejemplo dirige la discusión hacia un rasgo latente, pero reiterado en el discurso estudiantil, que tiene que ver con la reproducción que genera el actual sistema educacional de la discriminación y la desigualdad social. De esta forma, se observa cómo el espacio de debate que proporciona la comunidad de EI facilita y visibiliza la construcción de solidaridad y disenso entre sus miembros, permitiendo distinguir la heterogeneidad de posturas que los propios jóvenes mantienen sobre el conflicto educativo.

\section{- Meta-representación}

En la noticia son escasos los indicios lingüísticos que permiten reconstruir el modelo de contexto. Las referencias concretas provienen de ciertos nombres propios y circunstancias de tiempo y lugar que circunscriben el escenario en el que Sebastián Piñera ofrece sus declaraciones a un periódico extranjero en el marco de una gira presidencial. De la reposición, en cambio, se desprenden condiciones sociales más complejas en virtud de las cuales los seguidores de EI modelan la situación comunicativa sobre la cual se informa. En esta línea, sobresalen las condiciones de dilación y evasión que el gobierno ha creado para desgastar y desarticular las movilizaciones estudiantiles, así como las demostraciones de inflexibilidad e intransigencia que las mismas autoridades han mantenido durante los meses de manifestaciones. En (2) prevalecen estos actores en una relación de oposición, de modo que se simplifica el conflicto educativo al excluir otros participantes críticos como son, por ejemplo, la sociedad o la ciudadanía que resiente o reacciona ante los efectos de la crisis educacional, o bien, las elites económicas que reguardan y perpetúan el modelo vigente en su beneficio. Esta opción, no obstante, no es de extrañar si se considera que la noticia se construye exclusivamente desde la perspectivación del ex presidente.

Al respecto, si bien Piñera es quien adquiere un rol comunicativo central, su rol político es fuertemente cuestionado en los comentarios que activa la reposición, toda vez que se recupera en la interacción su doble afiliación político-empresarial (i.e.: ADV: “como él ya tiene todo..."). En esta dirección, la definición de los objetivos de ambos participantes sintetiza la búsqueda de intereses grupales subyacentes: mientras el gobierno propone mantener el rol del mercado en la educación, los estudiantes apuestan por transformar no sólo el modelo educativo, sino que el sistema neoliberal más general que lo sustenta (i.e.: NG: "Por algo se busca un cambio "estructural" (¿captan la palabra?)"). Las acciones predominantes confirman esta confrontación en tanto aportan a la defensa de tales fines antagónicos. Dicha disputa se representa mediante una estrategia semántico-cognitiva específica: la metáfora del padre estricto. En principio, es en la noticia donde se configura esta subordinación entre el ex presidente y los estudiantes movilizados, mientras que en la reposición esta relación se subvierte a partir de un conjunto de críticas y burlas con las cuales los jóvenes deslegitiman tanto su posición de poder como su autoridad moral.

En cuanto al esquema epistémico, la noticia releva, por un lado, dos conocimientos que se asumen ya interiorizados por los lectores: el detalle acerca de las demandas del movimiento, y la crisis de la educación superior ("grandes problemas como los que enfrentamos”). Por otro lado, la noticia provee varios conocimientos que se presentan 
como nuevos: datos acerca de las reformas del gobierno a la educación preescolar y escolar, cifras sobre el crecimiento de la matrícula universitaria, y antecedentes del plan de mejoramiento de la calidad educativa. La reposición, por su parte, junto con presuponer conocimientos contingentes sobre el decurso de las movilizaciones, principalmente en torno a las recientes negociaciones con el gobierno, da por sabida la extendida discusión sobre los efectos del lucro en la educación. Adicionalmente, la reposición actualiza conocimientos relativos al papel que desempeña la Prueba de Selección Universitaria (PSU) en la mantención de la segregación educativa, y a la precarización de la labor docente. Estos últimos alcances demuestran en qué medida los jóvenes enriquecen del debate educacional, introduciendo variables que no pueden deducirse fácilmente de la noticia.

La confrontación ideológica es más bien difusa en esta publicación. Por una parte, se distinguen actitudes que avalan que la educación sea concebida como un bien de consumo (i.e.: MBV: “y el problema de las universidades, siempre ha sido así, siempre se ha pagado”), con lo cual se consolida la relación entre capacidad de pago y movilidad social. Por otra parte, se identifican actitudes que reivindican que la educación sea concebida como un derecho, sobre todo para quienes no disponen de las condiciones económicas para aspirar a un desarrollo digno. Desde esta perspectiva, el movimiento estudiantil promueve un principio de justicia social que supone que los sectores acomodados de la sociedad deben abdicar a sus privilegios en beneficio de los más necesitados (i.e.: KFA: “que le bajen los sueldos a los ministros y senadores y con eso se paga demás la educación”).

En concordancia con lo anterior, el esquema identitario se construye fundamentalmente a partir del eje individual/social. De un lado, se encontrarían los jóvenes que acceden a la educación como una recompensa a sus méritos y sacrificios personales, mientras que, de otro lado, se situarían los jóvenes que se comprometen con la lucha social en pos del bien común. Respecto de las memorias intragrupales, únicamente se registran dos menciones a coyunturas históricas con las que se intenta explicar la crisis educacional desde el punto de vista de los estudiantes movilizados. Ambas aluden superficialmente a la dictadura militar como un momento de menoscabo o perjuicio del modelo educativo, cuyas consecuencias se experimentarían aún en la actualidad.

\section{CONCLUSIONES}

Este artículo se ha propuesto relevar un problema de estudio contingente y novedoso en el marco de las actuales movilizaciones sociales mediadas tecnológicamente. Se ha escogido un caso concreto para explicar cómo se producen, difunden e interpretan noticias relativas al movimiento estudiantil chileno en redes sociales. La fan page de Estudiantes Informados ha permitido averiguar cómo determinados usos discursivos colaboran en la construcción de representaciones críticas sobre la acción política juvenil, a partir de un modelo analítico que conjuga elementos lingüísticos y cognitivos a distintos niveles de realización e interacción. Este análisis muestra que cuando los administradores y usuarios del sitio seleccionan, insertan y comentan estas noticias, tienen lugar varios procesos comunicativos interrelacionados: a) la recontextualización de los contenidos periodísticos provenientes de la prensa 
tradicional; b) la resignificación de los participantes, las acciones y las situaciones que son objeto de la cobertura mediática, y; c) y la redefinición de los modelos mentales que incorporan conocimientos, ideologías, identidades y memorias en torno a dichos objetos.

En este trabajo se ha podido establecer la emergencia de un nuevo género discursivo online: la reapropiación noticiosa en Facebook. Al identificar y describir la unidad de análisis "publicación” en EI, se ha mostrado cómo la relación estructural de sus componentes (entrada: ${ }^{\text {noticia }}+$ comentarios: intervenciones de los seguidores) modula las formas de producción e interacción discursiva en un momento específico del reciente ciclo movilizatorio: los primeros meses de protesta caracterizados por sucesivas manifestaciones y ocupaciones públicas, de un lado, y por distintas instancias de debate y negociación política entre los estudiantes y las autoridades de gobierno, del otro. Como puede desprenderse del corpus escogido, son estas últimas coyunturas las que adquieren mayor popularidad y saliencia informativa en EI. Al respecto, se subrayan tres hallazgos interesantes que se resumen a continuación.

En primer lugar, se observa que la selección de noticias repuestas responde a la asignación de relevancia que efectúan los administradores de EI para determinar cuáles son las publicaciones que pueden generar mayores reacciones (me gusta, comentar, compartir) por parte de sus seguidores. De allí que se privilegien contenidos que construyen representaciones polémicas sobre la acción política juvenil, esto es, contenidos que incentiven la participación, el diálogo y la discusión entre los interlocutores. En segundo lugar, se verifica que estas intervenciones a menudo dan cuenta de posicionamientos juveniles confrontados, lo que cuestiona la existencia de una comunidad homogénea en términos ideológicos e identitarios. Esto se evidencia sobre todo a medida que progresan las manifestaciones y aumenta el flujo de publicaciones en $E I$, lo que permite conjeturar en qué medida la maduración de los ciclos de protesta afecta la constitución de dinámicas de comunicación más densas y complejas. En tercer lugar, se ha comprobado que los comentarios suelen recuperar conocimientos y memorias que no necesariamente se presuponen o implican en las noticias repuestas, no obstante, sí pueden derivarse de otros discursos estudiantiles que circulan en las redes sociales (Cárdenas 2014b, 2014c, 2016). De este modo, se puede proponer que sitios como $E I$ devienen en enclaves de importantes síntesis cognitivas, destinadas a profundizar los procesos enmarcadores que son afines a la movilización colectiva.

A partir de esta experiencia de investigación, se ha constatado que la reapropiación noticiosa en Facebook ha logrado una presencia destacada no solo en el contexto de las recientes movilizaciones estudiantiles, sino que también ha facilitado la visibilización de otros movimientos que han recurrido a la creación de una fan page para dar cuenta de los conflictos políticos que los involucran. En este punto, surge la necesidad de explicar cómo la utilización de este género adquiere una función determinada en contextos comunicativos y sociales marcados por disputas de poder. Al respecto, entre el conjunto de prácticas mediales activistas que los movimientos desarrollan cuando incorporan las tecnologías con finalidades contenciosas sobresale, como se ha demostrado hasta aquí, la de gestionar estratégicamente la información que les compete.

El estudio realizado puede aportar algunos antecedentes que ayuden a delimitar la práctica de gestión (contra)informativa en redes sociales. Esta no solo colabora a 
deconstruir la imposición unidireccional, monológica y jerárquica de los contenidos noticiosos, sino también a reinterpretarlos, controvertirlos y actualizarlos en un espacio interactivo, dialógico y autónomo. Por lo tanto, su función no consiste únicamente en desvelar la reproducción de sesgos, estereotipos o prejuicios que negativizan al movimiento estudiantil, sino además en legitimar las acciones e identidades de sus miembros con fines reivindicativos. Con ello, se activan dinámicas de producción e interacción discursiva que, al no depender ni estar supeditadas a las esferas adultas y poderosas, sirven a los objetivos de minimizar los efectos manipuladores de los medios hegemónicos, por un lado, y de profundizar los sentidos de afiliación y pertenencia de los actores movilizados, por el otro. Las redes sociales devienen, así, en emplazamientos prevalentes del discurso político juvenil. Su uso conduce, paulatinamente, a la expresión de nuevas relaciones de fuerza, pues, aunque la prensa tradicional a menudo represente a los estudiantes en un lugar subordinado respecto de las autoridades de gobierno, en la comunicación online ellos están constantemente subvirtiendo estas posiciones de poder, disputando su predominio e influencia. Esto repercute, con el tiempo, en la formación de una audiencia-ciudadanía crítica, que puede llegar a desestabilizar el rol dominante que las elites mediáticas ejercen sobre el control informativo.

Desde esta perspectiva, sitios como Facebook pueden favorecer la reformulación socio-cognitiva (Cárdenas 2014b), proporcionando al movimiento estudiantil los recursos simbólicos necesarios para crear su propio orden social (Pardo Abril 2009). Esto se cumple toda vez que sus miembros acceden e interactúan en un espacio mediático que involucra cohesión grupal, solidaridad, empatía y orden moral compartido. En este sentido, la base epistémica e ideológica que modula los procesos de comprensión e interacción juvenil en redes sociales desempeña un papel crucial en la conformación de comunidades online como EI. Como se ha intentado mostrar con este artículo, esta comunidad puede caracterizarse en virtud de los usos discursivos con que los que los jóvenes modelan intersubjetivamente los contextos, conocimientos, ideologías, identidades y memorias que conforman sus modos de representación colectiva. Su análisis promueve un área de investigación incipiente en el campo de los Estudios Críticos del Discurso, asociada con problemáticas que revelan diversos ejercicios de contrapoder o resistencia que merecen ser señalados y profundizados.

\section{OBRAS CITADAS}

Aguilera, Óscar. 2008. "Medios de comunicación en Chile, movimientos juveniles y políticas de la visibilidad”. Comunicação, Mídia e Consumo 5.14: 55-68.

2010. "Acción colectiva juvenil: De movidas y finalidades de adscripción”. Revista Nómadas 32: 81-98.

Aguirre, Félix y Óscar García. 2015. "Más allá de malestar. Una hipótesis sociológica sobre el significado político del movimiento estudiantil chileno". Revista de Sociologia e Política 23.53: $147-162$.

Arancibia, María Cristina y Lésmer Montecino. 2013. "El blog de comentarios a textos de opinión en ciberperiódicos: Un género en constante reconstrucción”. Revista Literatura y Lingüística 28: 123-148.

Stephen Sadlier y Lésmer Montecino. 2016. "Impact of social media on Chilean student movement”. En Kirsi Pauliina, Sarah Mills y Tracey Skelton (Eds.), Politics, citizen- 
ship and rights. Singapore: Springer. 331-344.

Bellei, Cristian y Cristian Cabalin. 2013. "Chilean student movements: Sustained struggle to transform a market-oriented educational system”. Current Issues in Comparative Education 15.2: 108-123.

y Víctor Orellana. 2014. "The 2011 Chilean student movement against neoliberal education policies”. Studies in Higher Education 39.3: 426-440.

Bennett, W. Lance. 2007. "Civic learning in changing democracies". En Dahlgren, Peter (Ed.), Young citizens and new media: Learning for democratic participation. London-New York: Routledge. 59-77.

y Alexandra Segerberg. 2013. The logic of connective action. Digital media and the personalization of contentious politics. Cambridge: Cambridge University Press.

Boyle, Michael et al. 2005. "Newspaper and protest: An examination of protest coverage from 1960-1999”. Journalism \& Mass Communication Quarterly 82.3: 638-653.

Cabalin, Cristian. 2012. "Neoliberal education and student movements in Chile: Inequalities and malaise". Policy Futures in Education 10.2: 219-228.

2013. "Framing y políticas educacionales: Los medios como actores políticos en educación”. Estudios sobre el Mensaje Periodístico 19.2: 635-647.

2014. "The conservative response to the 2011 Chilean student movement: Neoliberal education and media”. Discourse: Studies in the Cultural Politics of Education 35.4: 485-498.

Cárdenas, Camila. 2011. “Análisis de tres modos de representación ideológica construidos en discursos especializados sobre juventud chilena producidos entre 1970 y 1990”. Revista Latinoamericana de Estudios del Discurso 11.2: 28-48.

2012. “¿Dónde debe emplazar su ojo la historia? (In)visibilización de las y los jóvenes en discursos disciplinares que recuperan el pasado reciente chileno (1970-1990)”. Discurso \& Sociedad 6.2: 283-313.

2014a. “Jóvenes e (in)visibilización histórica: Modos de representación ideológica de la juventud chilena en el pasado reciente (1970-1990)”. Signos. Estudios de Lingüística 47.85: 217-244.

2014b. "Representación de la acción política de los estudiantes chilenos. Movilización de significados en redes sociales". Revista Última Década 22.40: 57-84.

2014c. "Inútiles y subversivos: Representación transmedia de los estudiantes chilenos en redes sociales”. Revista Romanica Olomucensia 26.2: 173-190.

2016. "Representación de la acción política juvenil en redes sociales: Análisis crítico de las prácticas discursivas producidas durante las movilizaciones estudiantiles en Chile (2011-2013)”. Revista Austral de Ciencias Sociales 30: 77-99.

Cárcamo, Luis y Diego Sáez. 2013. “¿Cambian las hegemonías periodísticas en las redes sociales? Prensa chilena en Facebook”. Recuperado el 15 de febrero de 2014, de http:// www.nhengatu.org/revista/index.php?journal=nhengatu\&page $=$ article\&op=download $\&$ path\%5B $\% 5 \mathrm{D}=6 \&$ path\%5B $\% 5 \mathrm{D}=5$

Castells, Manuel. 2007. "Communication, power and counter-power in the network society". International Journal of Communication 1: 238-266. 2009. Comunicación y poder. Madrid: Alianza Editorial. 2012. Redes de indignación y esperanza. Madrid: Alianza Editorial. 2014. "El poder de las redes". Vanguardia Dossier 50: 6-13.

Cohen, Stanley. 1973. "Mods and rockers: The inventory as manufactured news". En Cohen, Stanley y Jock Young (Eds.), The manufacture of news. Deviance social problems and mass media. London: Constable. 263-279.

Costanza-Chock, Sasha. 2012. “Mic check! Media cultures and the occupy movement”. Social Movement Studies 11.3-4: 375-385.

2013. "Transmedia mobilization in the Popular Association of the Oaxacan Peoples, 
Los Angeles”. En Cammaerts, Bart, Alice Mattoni y Patrick McCurdy (Eds.), Mediation and protest movements. Chicago: Intellect-The University of Chicago Press. 95-144.

De la Maza, Gonzalo. 2010. "La disputa por la participación en la democracia elitista chilena”. Latin American Research Review 45: 274-297.

Feixa, Carles, Inés Pereira y Jeffrey Juris. 2009. “Global citizenship and the ‘new, new’ social movements: Iberian connections”. Young 17.4: 421-442.

Ariadna Fernández-Planells y Mónica Figueras-Maz. 2016. “Generación Hashtag. Los movimientos juveniles en la era de la web social”. Revista Latinoamericana de Ciencias Sociales, Niñez y Juventud 14.1: 107-120.

Garcés, Mario. 2013. "El movimiento estudiantil y la crisis de legitimidad de la política chilena”. Revista Pensar Historia 2: 83-93.

Garretón, Manuel Antonio et al. 2011. "Movimiento social, nuevas formas de hacer política y enclaves autoritarios. Los debates del Consejo Asesor para la Educación en el gobierno de Michelle Bachelet en Chile”. Polis. Revista Latinoamericana 10.30: 117-140.

Herring, Susan. 2013. "Discourse in Web 2.0: Familiar, reconfigured, and emergent". En Tannen, Deborah y Anna Marie Trester (Eds.), Discourse 2.0: Language and new media. Washington: Georgetown University Press. 1-26.

Iedema, Rick. 2003. "Multimodality, resemiotization: Extending the analysis of discourse as multi-semiotic practice”. Visual Communication 2.1: 29-57.

Klandermans, Bert y Sjoerd Goslinga. 1999. "Discurso de los medios, publicidad de los movimientos y la creación de marcos para la acción colectiva: Ejercicios teóricos y empíricos sobre la construcción de significados". En McAdam, Dough, John McCarthy y Mayer Zald (Eds.), Movimientos sociales: Perspectivas comparadas. Madrid: Itsmo. 442-474.

Kress, Gunther. 2010. Multimodality: A social semiotic approach to contemporary communication. London-New York: Routledge.

Lakoff, George y Mark Johnson. 1986. Metáforas de la vida cotidiana. Madrid: Cátedra.

Lasswell, Harold. 1927. Propaganda technique in the world war. New York: MIT Press.

Lemke, Jay. 2005. "Critical analysis across media: Games, franchises, and the new cultural order”. En Labarta Postigo, María (Ed.), Approaches to Critical Discourse Analysis. Valencia: Universidad de Valencia. 1-22.

2009. “Transmedia traversals: Marketing meaning and identity”. En Baldry, Anthony y Elena Montagna (Eds.), Interdisciplinary perspectives on multimodality: Theory and practice. Proceedings of the Third International Conference on Multimodality. Campobasso: Palladino. 576-596.

. 2013. "Multimedia and discourse analysis". En Gee, James Paul y Michael Handford (Eds.), Routledge Handbook of Discourse Analysis. London-New York: Routledge. 7989.

Maletzke, Gerhard. 1964. Psicología de la comunicación colectiva. Quito: CIESPAL.

Martín Rojo, Luisa. 2013. "Paisajes lingüísticos de indignación. Prácticas comunicativas para tomar las plazas”. En Aguilar, Salvador (Ed.), Anuario del conflicto social 2012. Barcelona: Observatorio del Conflicto Social-Universidad de Barcelona. 275-302.

Mattoni, Alice. 2013. "Repertoires of communication in social movement processes". En Cammaerts, Bart, Alice Mattoni y Patrick McCurdy (Eds.), Mediation and protest movements. Bristol-Chicago: Intellect. 39-56.

Mayol, Alberto y Carla Azócar. 2011. "Politización del malestar, movilización social y transformación ideológica: El caso “Chile 2011”. Polis. Revista Latinoamericana 10.30: 2-16.

. 2012. El derrumbe del modelo. La crisis de la economía de mercado en el Chile contemporáneo. Santiago: LOM.

McCombs, Maxwell y Donald Shaw. 1972. "The agenda-setting function of mass media”. Public Opinion Quarterly 36.2: 176-187. 
McLeod, Douglas. 2007. "News coverage and social protest: How the media's protest paradigm exacerbates social conflict". Journal of Dispute Resolution 1: 185-194.

Millaleo, Salvador. 2011. "La ciberpolítica de los movimientos sociales en Chile: Algunas reflexiones y experiencias". Revista Anales 7.2: 89-104.

Montecino, Lésmer. 2011. “¿Por qué marchan los estudiantes en Chile?: Discurso electrónico y poder en un ciberperiódico”. Cadernos de Linguagem e Sociedade 12.2: 179-209.

Muñoz, Víctor, Carlos Durán y Eduardo Thayer. 2014. "Los jóvenes populares urbanos frente a la prensa escrita y digital: Distorsiones, identificaciones, distancias y silencios". Revista Última Década 22.41: 89-123.

Oliva, María Angélica. 2008. "Política educativa y profundización de la desigualdad en Chile”. Estudios Pedagógicos 34.2: 207-226. 2010. “Política educativa chilena 1965-2009. ¿Qué oculta esa trama?”. Revista Brasileira de Educação 15.44: 311-328.

Orlandi, Eni. 2012. Análisis de discurso. Principios y procedimientos. Santiago: LOM-UMCE. Pardo Abril, Neyla. 2007. Discurso, impunidad y prensa. Bogotá: Centro Editorial Facultad de Ciencias Humanas, Universidad Nacional de Colombia. 2009. "Los bordes en la significación discursiva y la mediación mediatizada". Revista Comunicación y Ciudadanía 1: 54-73.

2012. Discurso en la Web: Pobreza en Youtube. Bogotá: Centro Editorial Facultad de Ciencias Humanas, Universidad Nacional de Colombia.

Pérez, Carolina. 2012. "The Chilean student movement and the media: A comparative analysis on the linguistic representation of the 04 August, 2011 manifestation in right-wing and left-wing newspapers”. Logos. Revista de Lingüística, Filosofía y Literatura 22.2: 4-26. 2016. "La representación visual del movimiento estudiantil chileno en la prensa establecida y alternativa nacional: Un análisis multimodal”. Revista Austral de Ciencias Sociales 30: 5-26.

Rovira Sancho, Guiomar. 2015. "De las redes activistas a las multitudes conectadas. Movilización social, protesta global y tecnologías de la comunicación”. Revista Internacional de Pensamiento Político 10: 157-170.

Salinas, Daniel y Pablo Fraser. 2012. "Educational opportunity and contentious politics: The 2011 Chilean student movement”. Berkeley Review of Education 3.1: 17-47.

Shoemaker, Pamela. 1984. "Media treatment of deviant political groups". Journalism Quarterly 61.1: 66-82.

Sierra Caballero, Francisco. 2013. “Comunicología y tecnopolítica emergente. Nuevas mediaciones y espacios de liberación social”. Revista de Estudios para el Desarrollo Social de la Comunicación. Redes.com 8: 11-18.

Somma, Nicolás. 2012. "The Chilean student movement of 2011-2012: Challenging the marketization of education”. Interface: A Journal for and about Social Movements 4.2: 296309.

Tarrow, Sidney. 2011. El poder en movimiento. Los movimientos sociales, la acción colectiva y la política. Madrid: Alianza Editorial.

Tilly, Charles y Leslie Wood. 2010. Los movimientos sociales, 1768-2008. Desde sus orígenes a Facebook. Crítica: Barcelona.

Torche, Florencia. 2005a. "Privatization reform and inequality of educational opportunity: The case of Chile". Sociology of Education 78.4: 316-343.

2005b. "Unequal but fluid: Social mobility in Chile in comparative perspective". American Sociological Review 70.3: 422-450.

Toret, J. (Coord.). 2015. Tecnopolítica y 15M: La potencia de las multitudes conectadas. Un estudio sobre la gestación y explosión del 15M. Barcelona: UOC Ediciones.

Van Dijk, Teun. 1990. La noticia como discurso. Comprensión, estructura y producción de la información. Barcelona: Paidós Comunicación. 
2002. “El conocimiento y las noticias”. Quaderns de Filologia 1: 249-270.

2009. Discurso y poder. Barcelona: Gedisa.

2010a. "Political identities in parliamentary debates". En Ilie, Cornelia (Ed.), European parliaments under scrutiny. Discourse strategies and interaction practices. Amsterdam: Benjamins. 29-56.

2010b. "Discurso, conocimiento, poder y política. Hacia un análisis crítico epistémico del discurso". Revista de Investigación Lingüística 13: 167-215.

2011. Sociedad y discurso. Barcelona: Gedisa.

2012. Discurso y contexto. Barcelona: Gedisa.

2014. Knowledge and discourse. Cambridge: Cambridge University Press.

Van Leeuwen, Theo. 2008. Discourse and practice. New tools for Critical Discourse Analysis. Oxford: Oxford University Press.

Yus, Francisco. 2010. Ciberpragmática 2.0. Nuevos usos del lenguaje en Internet. Barcelona: Ariel. 
